\title{
VII
}

\section{OS SIGNIFICADOS DA EJA PARA OS JOVENS DE 15 A 17 ANOS EM ANGRA DOS REIS*}

\author{
Leila Mattos Haddad de Monteiro Marinho ${ }^{1}$
}

O presente capítulo, fruto da dissertação de Mestrado defendida no Programa de Pós-Graduação em Educação da Universidade Federal Fluminense em 2015, procura refletir sobre as relações que os jovens de 15 a 17 anos, alunos da Educação de Jovens e Adultos (EJA) da rede municipal de educação de Angra dos Reis, estabelecem com a escolarização e a escola. O objetivo da pesquisa consistiu em investigar a relação pessoal que esses jovens estabelecem com a escolarização, com a escola e, mais especificamente, com a Educação de Jovens e Adultos, principalmente compreendendo como esses jovens se veem dentro da EJA e o significado da EJA em suas vidas.

A metodologia utilizada foi a abordagem biográfica, que procura recuperar as trajetórias dos sujeitos para "compreender as experiências vividas em determinadas situações sociais” (COSTA, 2011, p. 16).

A partir da realização de entrevistas, a pesquisadora retoma relatos dos jovens sobre suas trajetórias, tomando-os como sujeitos de sua própria história.

Os jovens entrevistados foram selecionados a partir da aplicação de questionários, entre os alunos de 15 a 17 anos, a fim de traçar o perfil dos jovens da EJA: idade, gênero, estado civil, trajetória escolar, perfil familiar e hábitos de lazer.

A fim de compreender quem são e de onde vem esses jovens, o trabalho se baseou em dados do IBGE, principalmente do IBGE - Cidades, e nos dados da pesquisa Perfil da EJA², realizada pela Coordenação da Educação de

${ }^{*}$ DOI - 10.29388/978-65-86678-41-3-0-f.153-172

1 Licenciatura em História, mestre em Educação pela Universidade Federal Fluminense. Professora de História da Rede Municipal de Angra dos Reis. Ex-coordenadora de Educação de Jovens e Adultos da Secretaria Municipal de Educação de Angra dos Reis.

${ }^{2}$ A referida pesquisa visava traçar um perfil dos alunos da EJA de Angra dos Reis nos períodos assinalados. Através desse material foi possível conhecer melhor a modalidade dentro da rede de ensino do município: informações sobre distribuição de gênero, cor/raça, renda, condição familiar (número de filhos, quantidade de pessoas por moradia, renda), condição socioeconômica (se paga aluguel, se tem trabalho com carteira assinada), além de informações sobre seus interesses escolares e extraescolares (disciplinas onde encontra maior dificuldade ou preferência, atividades que são realizadas na escola como teatro, filmes, palestras etc. e ainda se realiza outras 
Jovens e Adultos da Secretaria de Educação, Ciência e Tecnologia entre os anos de 2010 e 2012.

\section{Panorama dos Jovens na EJA}

A presença de um número cada vez maior de jovens na Educação de Jovens e Adultos vem sendo apontada por diversos autores como uma questão a ser enfrentada por todos aqueles que direta ou indiretamente estão envolvidos com a educação, seja no papel de educador, gestor ou legislador.

Segundo dados do IBGE-PNAD 2011 (BRASIL, 2012), o percentual de jovens entre 15 e 24 anos na educação de jovens e adultos era de $35,8 \%$. Na região Sudeste, representava 30,9\%; na região Centro-Oeste 29,1\%; no Nordeste, 37,9\%; na região Sul, 41,0\% e Norte, 41,2\%. Estas três últimas regiões apresentavam os maiores percentuais de jovens na EJA.

Entre os grupos mais encontrados nos cursos de alfabetização e de educação de jovens e adultos, ainda segundo o documento, são os grupos compostos por pessoas que têm de 25 a 59 anos de idade. Eles representavam $50,7 \%$, dos quais a maior parte são mulheres $(57,9 \%) ; 70,8 \%$ pretos ou pardos; $50,8 \%$ residiam na Região Nordeste e 68,3\% em áreas urbanas.

É importante ainda ressaltar que, de acordo com o PNAD, as regiões com os menores índices de frequência escolar, nessa mesma faixa etária, eram as regiões Norte $(41,3 \%)$ e Nordeste $(43,0 \%)$, enquanto nas demais regiões a frequência superava os $50 \%$ dos alunos matriculados: na região Sul é de 55,5\%, enquanto que no Centro-Oeste, 57,0\% e no Sudeste de 59,8\%.

Os menores percentuais de frequência à escola estavam entre os pretos e pardos, $45,3 \%$, enquanto $60,0 \%$ dos alunos frequentes eram brancos.

Também chamava atenção o fato de que entre a população de mais baixa renda, apenas $36,8 \%$ dos jovens estavam frequentando a escola, enquanto que, entre os mais ricos, $74,5 \%$ frequentavam.

Esses dados evidenciam o quanto, a despeito da universalização do acesso à escola da década de 1990, a educação no Brasil permanece como um privilégio e ainda se mantém distante da efetiva conquista enquanto direito.

No estado do Rio de Janeiro, segundo dados do censo escolar de 2014 da Secretaria de Estado de Educação (SEEDUC), apenas 47,8\% dos jovens na faixa etária entre 15 a 17 anos estavam cursando a série adequada a sua faixa estaria, isto é, o ensino médio; e 18,9\% dos alunos das escolas estaduais estavam

atividades ou frequenta cursos na comunidade em que vive). 
matriculados na educação de jovens e adultos, frequentando os ensinos fundamental e médio (presencial e semipresencial).

Se tradicionalmente a EJA visava atender o público adulto trabalhador, que abandonou a escola há muitos anos (ou mesmo não chegou a entrar), levado por questões sociais, econômicas, pessoais ou de outra ordem, esse quadro vem se alterando. Cada vez mais a EJA é procurada por jovens que se deslocam do ensino chamado regular.

Em Angra dos Reis, esse fato é uma realidade. A maior parte dos jovens que ingressam na EJA, geralmente o fazem na II Etapa, que corresponde aos anos finais do ensino fundamental e muitos trazem um histórico de retenções.

Segundo dados do censo de 2010, no município de Angra dos Reis havia 119 jovens de 15 a 17 anos que nunca frequentaram creche ou escola ${ }^{3}$; na cidade do Rio de Janeiro, esse quantitativo é de 5.362 jovens. São milhares de jovens analfabetos, que se encontram totalmente excluídos de uma participação efetiva na sociedade letrada. O que nos mostra a necessidade urgente de avançar inclusive na oferta da educação de jovens e adultos para aqueles que ainda não tiveram acesso a esse direito.

Seguindo o fluxo contrário ao que as pesquisas indicam, o governo estadual e os governos municipais (especialmente das cidades do Rio de Janeiro e de Angra dos Reis) têm fechado turmas de EJA, reduzindo ainda mais a oferta de vagas que, ademais, já não atendia plenamente a demanda.

Em Angra dos Reis, o fechamento se dá sob a justificativa de otimização da administração e a alegação de turmas esvaziadas e término das aulas antes do horário. Outra razão alegada para o fechamento de escolas que atendem a EJA é a violência em diversas localidades, impossibilitando a permanência do funcionamento das escolas no período noturno.

O ano de 2018, de fato, tem sido marcado, sobretudo nos municípios do Rio de Janeiro e Angra dos Reis, pelo acirramento da violência urbana, no entanto, o fechamento de algumas unidades não passou por uma discussão com as comunidades na busca por soluções alternativas para a população que acabou ficando sem nenhuma possibilidade de acesso à escolarização.

A pesquisa Perfil da EJA realizada pela Coordenação de EJA da Secretaria Municipal de Educação de Angra dos Reis, por sua vez, evidencia o rápido

\footnotetext{
${ }^{3}$ Para o país e regiões, o IBGE - Censo 2010 - apresenta tabelas dos analfabetos. No IBGE cidades os dados aparecem como pessoas com Ensino Fundamental incompleto e pessoas que não frequentam e nunca frequentaram a escola.
} 
crescimento do número de jovens de 15 a 17 anos na EJA da cidade, especialmente na II Fase - anos finais do Ensino Fundamental ( $6^{\circ}$ ao $9^{\circ}$ ano).

Em 2010, os jovens abaixo dos 20 anos eram 25,79\% deste público em Angra dos Reis. Em 2012, eles já representavam 41,03\% desse total. Quanto aos jovens de 15 a 17 anos, no primeiro semestre de 2012, representavam 29,44\% deste público. Sendo, 1,36\% se matriculou na I Fase da I Etapa (alfabetização $/ 1^{\circ}$ ano de escolaridade), $24,62^{\%}$ na I Fase da II Etapa ( $6^{\circ}$ ano de escolaridade) e 24,79\% na II Fase da II Etapa ( $7^{\circ}$ ano de escolaridade).

Os dados mostram que os adolescentes da EJA hoje possuem passagens pela escola. No entanto, essa escolaridade é caracterizada por percursos truncados, contando com inúmeras interrupções e/ou retenções provocadas pela necessidade de se inserir no mercado de trabalho, gravidez precoce, não aprendizado e consequente perda de interesse que levam a infrequência e repetências.

Não é incomum o abandono da escola por adolescentes que precisam ficar em casa cuidando dos irmãos mais novos, sobrinhos, os próprios filhos ou porque precisam trabalhar para complementar a renda familiar.

Portanto, essa EJA que temos hoje é bastante diversa daquela de décadas passadas, quando o público era basicamente de adultos trabalhadores analfabetos (ou quase), que não tiveram passagem pela escola (ou o fizeram muito rapidamente).

Os dados apontam que esses meninos e meninas são jovens escolarizados, que se transferem, ou são transferidos, do ensino regular diretamente para a EJA.

Na pesquisa Perfil da EJA de 2010, encontramos 26\% dos alunos com menos de 20 anos, $60 \%$ na faixa etária entre 21 a 50 anos; e apenas $14 \%$ maiores de 50 anos.

Em 2012 esse grupo cresceu consideravelmente: 41\% tinha menos de 20 anos, $52 \%$ na faixa etária entre 21 a 50 anos e $7 \%$ mais de 50 anos.

Analisando os números da Unidade Escolar selecionada para a fase qualitativa da pesquisa, também notamos uma elevação na quantidade de jovens. Havendo, inclusive, turmas formadas essencialmente por esses jovens.

Longe de minimizar o problema da juvenilização da EJA, esses dados suscitam outras questões importantes: quem são esses jovens que estão vindo para a EJA? Qual é a representação que os professores fazem dos jovens e da juventude? Como se dá a relação intergeracional dentro da EJA: dos jovens 
com os adultos e com os idosos? E, por fim, como o próprio jovem se vê, enquanto sujeito que está na EJA?

Questionamentos sobre as relações desses jovens com o espaço da escola, especialmente da EJA, sua permanência, abandono e retorno a esse espaço continuam sem respostas. As relações que se estabelecem entre as práticas sociais e vida escolar desses jovens também estão por serem estudadas. As discussões feitas nesse campo demonstram que a escola permanece muito distante dos sonhos, ou mesmo da realidade da juventude.

Os questionamentos sobre o lugar do jovem na Educação de Jovens e Adultos têm adquirido destaque nas discussões dos docentes da EJA em todo Brasil, não sendo diferente em Angra dos Reis. Apresenta-se, de forma cada vez mais contundente, que é preciso considerar conhecer esses jovens, seus anseios, sua trajetória de vida, suas dificuldades e sonhos, para, a partir desse conhecimento, traçar novos caminhos não só para a Educação de Jovens e Adultos, mas para a Educação de maneira geral. Caminhos esses que levem à permanência desses jovens na escola, seja na EJA ou, preferencialmente, no regular e à conclusão de sua escolarização.

Os dados nos mostram o quão distantes estamos de construir essa escola includente e acolhedora, que veja o jovem como sujeito de direitos e também de vontades, sonhos, anseios, gostos e fazeres próprios.

Essa escola expulsa os jovens e os faz procurar a Educação de Jovens e Adultos como o último recurso, a última tentativa de concluir a escolarização.

Tabela 1 - Matrículas no Ensino Fundamental na rede municipal de Angra dos Reis - 2009-2013

\begin{tabular}{|c|c|}
\hline Nível de ensino & Número de matrículas \\
\hline \multicolumn{2}{|c|}{$\mathbf{2 0 0 9}$} \\
\hline Primeiro ano & 52.547 \\
\hline Sexto ano & 84.934 \\
\hline Nono ano & 54.783 \\
\hline \multicolumn{2}{|c|}{} \\
\hline Primeiro ano & $\mathbf{2 0 1 0}$ \\
\hline Sexto ano & 71.992 \\
\hline Nono ano & 47.361 \\
\hline \multicolumn{2}{|c|}{} \\
\hline Primeiro ano & $\mathbf{2 0 1 1}$ \\
\hline Sexto ano & 52.696 \\
\hline Nono ano & 60.521 \\
\hline \multicolumn{2}{|c|}{} \\
\hline Primeiro ano & $\mathbf{2 0 1 2}$ \\
\hline
\end{tabular}




\begin{tabular}{|c|c|}
\hline Sexto ano & 63.803 \\
\hline Nono ano & 44.659 \\
\hline \multicolumn{2}{|r|}{2013} \\
\hline Primeiro ano & 50.773 \\
\hline Sexto ano & 66.428 \\
\hline Nono ano & 43.226 \\
\hline
\end{tabular}

Fonte: IBGE, 2010.

Quando comparamos o número de crianças que entram no ensino fundamental e quantas chegam ao final dele, percebemos através da análise dos dados acima que muitas ficaram pelo caminho.

Se entre o primeiro e o sexto ano se verifica aumento na quantidade de matrículas, do sexto para o nono ano podemos ver uma sensível redução no número de alunos matriculados.

Em qualquer período considerado, verificamos que há uma redução na quantidade de alunos ao final do ensino fundamental, o que significa que boa parte das crianças que ingressam nos anos iniciais do primeiro e do segundo segmentos não completam o ensino fundamental e, consequentemente, não chegam ao ensino médio. Esses são os sujeitos que se constituirão no público da EJA.

Tabela 2 - Matrícula no Ensino Fundamental e Ensino Médio em Angra dos Reis - 2005/2007/2009/2012

\begin{tabular}{|c|c|c|c|c|}
\hline $\begin{array}{c}\text { Nível } \\
\text { Ano de Ensino }\end{array}$ & $\mathbf{2 0 0 5}$ & $\mathbf{2 0 0 7}$ & $\mathbf{2 0 0 9}$ & $\mathbf{2 0 1 2}$ \\
\hline Ensino Fundamental & 30.052 & 28.640 & 28.938 & 26.742 \\
\hline Ensino Médio & 7.500 & 7.267 & 7.401 & 6.959 \\
\hline
\end{tabular}

Fonte: Censo Demográfico 2010 - IBGE Cidades

A tabela acima nos mostra que o número de matrículas no ensino médio no município é sensivelmente inferior à quantidade de matrículas no ensino fundamental.

Segundo dados do Censo demográfico de 2010, a população de 10 a 14 anos no município era de 16.135 pessoas, e desse grupo 15.539 (96,3\%) frequentavam a escola. Entre os jovens de 15 a 17 anos, havia no município 8.994, dos quais $7.672(85,3 \%)$ frequentavam a escola. Mas a quantidade de jovens que chegam ao ensino médio ainda é reduzida frente ao número de matrículas no ensino fundamental. 
No que diz respeito à Educação de Jovens e Adultos, conforme tabela 3, no âmbito do município de Angra dos Reis, os números são modestos com relação à procura pela EJA. Apenas $0,4 \%$ da população do município frequentava cursos de alfabetização, 1\% se matriculou no Ensino Fundamental e 0,8\% no Ensino Médio.

Tabela 3 - Pessoas que frequentavam a EJA no Município de Angra dos Reis/ 2010

\begin{tabular}{|c|c|c|c|c|c|c|c|c|}
\hline \multicolumn{9}{|c|}{ População total do Município - 169.511} \\
\hline \multicolumn{2}{|c|}{ Alfabetização } & \multirow{2}{*}{$\begin{array}{c}\% \text { total } \\
\text { e parci- } \\
\mathbf{a l}^{4}\end{array}$} & \multicolumn{2}{|c|}{$\begin{array}{c}\text { Ensino } \\
\text { Fundamental }\end{array}$} & \multirow{2}{*}{$\begin{array}{c}\begin{array}{c}\% \text { total e } \\
\text { parcial }\end{array} \\
1,0\end{array}$} & \multicolumn{2}{|c|}{$\begin{array}{l}\text { Ensino } \\
\text { Médio }\end{array}$} & \multirow{2}{*}{$\begin{array}{c}\begin{array}{c}\% \text { total e } \\
\text { parcial }\end{array} \\
0,8\end{array}$} \\
\hline Total & 743 & & Total & 1.766 & & Total & 1.442 & \\
\hline $\begin{array}{c}\text { Particu- } \\
\text { lar }\end{array}$ & 22 & 3,0 & $\begin{array}{l}\text { Parti- } \\
\text { cular }\end{array}$ & 75 & 4,2 & $\begin{array}{l}\text { Parti- } \\
\text { cular }\end{array}$ & 243 & 16,9 \\
\hline Pública & 721 & 97,0 & Pública & $1.691^{5}$ & 95,8 & Pública & 1.199 & 83,1 \\
\hline
\end{tabular}

Fonte: IBGE Cidades - Censo Demográfico 2010.

Se levarmos em consideração a enorme quantidade de pessoas com pouca ou nenhuma instrução no município, entendemos que a demanda pela Educação de Jovens e Adultos em Angra dos Reis ainda é bastante elevada.

Com certeza, após as últimas medidas de fechamento de diversas turmas da EJA na rede municipal, a demanda cresceu ainda mais do que esta que se apresentava em 2010/2012 .

\section{Os sujeitos jovens na/da EJA}

Em Angra dos Reis, desde a década de 1990, o Regular Noturno tinha a tradição de atender o aluno adulto fora da escola há muitos anos ou mesmo não escolarizado. O perfil do alunado era de migrante, principalmente nordestino, que acorreu em busca de trabalho e novas oportunidades de vida nos períodos das grandes obras na região Costa Verde do estado do Rio de Janeiro.

\footnotetext{
${ }^{4} \mathrm{O}$ percentual total refere-se ao total de matrículas na fase/ano representada no total da população do município. Percentual parcial refere-se ao de alunos matriculados, respectivamente, na rede particular ou pública do município, em relação ao número total de matrículas.

${ }^{5}$ Esse dado não aparece no Censo IBGE 2010 Cidades - Angra dos Reis. Foi organizado através da subtração do número de matrículas nos estabelecimentos de ensino particulares do total de matrículas na EJA no Ensino Fundamental no Município.

${ }^{6}$ Entre 2017 e 2018, quatro unidades que atendiam a EJA no continente e uma na Ilha tiveram suas atividades encerradas sob alegação de otimização do atendimento/investimento.
} 
O novo perfil de alunos jovens, muitos não trabalhadores, vem causando estranheza aos professores. E, em muitos casos, resistências. No entanto, a presença desses jovens na EJA não se limita a uma problemática local. Ultimamente, o crescimento do número de jovens a partir dos 15 anos na educação de jovens e adultos tem sido anunciada e discutida.

Essa tendência vem sendo apontada, pelo menos desde a década de 1980, quando Vargas (1984) chama atenção para o crescimento do número de jovens a partir dos 14 anos no ensino supletivo, após a promulgação da lei $n^{\circ}$ 5.692/71. Isso se deu em consequência das dificuldades dos sistemas estaduais de ensino atenderem a crianças e adolescentes entre os 7 e 14 anos, a partir da extensão da obrigatoriedade de escolarização mínima de 4 para 8 anos.

Esse público da EJA em potencial está sendo produzido no regular, através das retenções, abandonos e infrequência desses jovens e a consequente defasagem idade/ano de escolaridade.

Os questionamentos sobre o lugar do jovem na Educação de Jovens e Adultos têm adquirido destaque nas discussões dos docentes da EJA em todo Brasil, não sendo diferente em Angra dos Reis.

Quem é o jovem que hoje vai para a EJA? Como ele se percebe enquanto estudante e enquanto ser social? Quais são os seus contextos? O que os move? Que escola procuram? Essas não são questões de respostas simples.

O jovem de que falamos aqui, é o jovem que evade, que entra tardiamente na escola, que não se encontra na escola formal e se perde na escola informal da vida.

Não é simples nem fácil lidar com esses jovens dentro da escola. Infelizmente, a escola não está preparada para os anseios e desejos desses jovens. Eles, por outro lado, não sabem bem o que esperar da escola, embora ainda acreditem na sua importância, e se frustrem com o que encontram intramuros. Uma realidade tão fora da sua realidade, de tudo o que vivem e experimentam no seu contexto familiar, geográfico, social e cultural.

A educação de jovens e adultos, conforme previsto na LDB (Lei 9394/1996), é uma modalidade da educação básica voltada para minimizar as desigualdades sociais, visto que se destina a dar acesso à escolarização àqueles que não tiveram na idade considerada própria.

Essa juvenilização tem causado impacto na EJA, principalmente pelo incômodo que causa, uma vez que provoca a mudança no perfil dos sujeitos da modalidade. 
Os jovens trazem para a EJA uma nova forma de relação com a escola. Eles não se afastaram da escola como o aluno adulto. Sua relação com a escola, muitas vezes difícil, é recente. Estes jovens não costumam ser passivos em sua relação com a escola, além de trazer interesses diferentes dos seus colegas mais velhos.

Por tudo isso, a juvenilização incomoda, posto que ela exige uma nova postura, novas abordagens e métodos de trabalho na EJA.

O lugar desse jovem na escola constituiu-se em um problema. Velhos para o ensino regular, esses jovens não tinham lugar na escola regular e foram colocados na EJA como forma de resolver o problema, no entanto, são considerados por muitos, jovens e imaturos demais para a Educação de Jovens e Adultos.

A obrigatoriedade do atendimento no Ensino Regular até os 14 anos é vista como uma restrição à frequência dos jovens a partir dos 15 anos nessa modalidade. Nesse sentido, e apesar de a resistência por parte de alguns professores, a EJA tem se mostrado mais acolhedora, pelo menos no âmbito da legalidade, em aceitar os jovens a partir dos 15 anos em suas salas como sujeitos dessa modalidade.

Em se tratando da Educação de Jovens e Adultos, é importante delimitar de que sujeitos estamos falando. É importante, mas não suficiente, a referência marxista de classes. Precisamos ir além, sem, no entanto, desprezar esse aspecto. A emergência de movimentos que reivindicam o reconhecimento político e cultural de identidades sociais específicas (mulheres, negros, jovens, indígenas, sem-terra) favoreceu o reconhecimento da diversidade dos sujeitos da EJA. Dentro dessa diversidade, há a questão da "juvenilização" sobressai.

Nessa perspectiva, os problemas vivenciados em salas de aula com forte presença de jovens estão mais relacionados ao fato de não sabermos como lidar com as expectativas desses sujeitos com relação à escola e à escolarização, com as suas representações do social e com seus hábitos e comportamentos, com sua cultura, do que com questões disciplinares, como pode parecer em um primeiro momento. Os modelos de aula e de escola que conhecemos, e que esses meninos e meninas também conhecem, não atendem a seus anseios. Por outro lado, os professores esperam dos jovens comportamentos e atitudes que supõem um "capital cultural" que eles não possuem.

A instituição escolar é organizada para homogeneizar, estabelecer normas e limites para as relações sociais, procurando dar conta de todos os aspectos dessas relações dentro do espaço escolar. Nesse sentido, como explicita 
Dayrell (1996), a escola é o resultado do confronto de interesses, contrapondo a organização escolar, com seus conteúdos, regras, hierarquização dos espaços e os sujeitos - alunos, professores, funcionários. Nesse sentido, a escola se constitui, segundo ele, como um espaço de permanente construção social cotidiana.

A escola colocada como instituição homogeneizadora, reduz a compreensão da educação e de seus processos a uma forma de instrução centrada na transmissão de informações. Reduz os sujeitos a alunos, e a diversidade desses sujeitos se perde nessa pretensa democratização. É preciso levar em conta que os alunos chegam à escola marcados pela diversidade, reflexo dos desenvolvimentos cognitivo, afetivo e social, evidentemente desiguais, em virtude da quantidade e qualidade de suas experiências e relações sociais, prévias e paralelas à escola. O tratamento uniforme dado pela escola só vem consagrar a desigualdade e as injustiças das origens sociais dos alunos.

Apreender esses jovens que chegam à escola como sujeitos socioculturais, implica em superar a visão homogeneizante e estereotipada da noção de aluno, dando-lhe outro significado. "Trata-se de compreendê-lo na sua diferença, enquanto indivíduo que possui uma historicidade, com visões de mundo, escalas de valores, sentimentos, emoções, desejos, projetos, com lógicas de comportamentos e hábitos que lhe são próprios" (DAYRELL, 1996, p. 4). Que cada um deles, ao chegar à escola, é fruto de um conjunto de experiências sociais vivenciadas nos mais diferentes espaços sociais. Assim, para compreendê-lo, temos de levar em conta a dimensão da experiência de vida de cada um, mesmo os mais jovens.

Levar em conta as experiências de vida significa produzir espaços escolares em que esses jovens se reconheçam como sujeitos, não apenas como alunos "histórica e territorialmente situados e impossíveis de conhecer a partir de definições gerais e abstratas" (CARRANO, 2007, p. 2).

O sujeito, dentro de um contexto histórico, social e cultural se move, em maior ou menor grau, estabelecendo suas escolhas e desenvolvendo meios de sobrevivência nesses contextos. A indisciplina, por exemplo, pode ser vista como um suporte do qual os jovens lançam mão para lidar com a inadequação da realidade escolar as suas expectativas ou interesses. Portanto, se toda escolha se concebe e se realiza dentro de um contexto, elas também são individuais (MARTUCCELLI, 2010).

Neste sentido, conhecer e entender os suportes criados/usados pelos jovens na EJA em Angra dos Reis pode contribuir para compreender suas trajetórias. 
Podemos começar a pensar essas questões a partir do próprio perfil desse jovem que se encontra na educação de jovens e adultos hoje. Diferente do jovem de décadas passadas, em que a característica principal do aluno era o trabalhador clássico, o operário de fábrica, mesmo quando bem jovem; hoje lidamos com outro perfil de jovem, outro trabalhador.

Arroyo (2007, p. 2) já nos apontava as perguntas essenciais que povoam a existência desses novosjovens: "que traços têm caracterizado ou que marcas poderíamos encontrar na construção dos jovens e adultos populares? O que lhes afeta mais? O que os desestrutura? O que os interroga? Como eles se interrogam sobre si mesmos, sobre a sua própria construção?"

Segundo o autor, não houve a esperada integração das camadas populares à sociedade de bem estar e de consumo. Ao contrário, esses sujeitos foram ficando cada vez mais segregados. Na ordem neoliberal, o que se postula é a ocupação decente, em lugar do emprego, delegando ao indivíduo a responsabilidade por seu sucesso ou fracasso.

Nesse contexto, o indivíduo se encontra cada vez mais isolado, sozinho para vencer as provas que lhe são impostas. Seria a EJA um suporte para esses jovens, do qual lançam mão quase como um último recurso para vencer essas provas? Seria a EJA o caminho para a socialização, que segundo Martuccelli (2010), é tão importante para nós, latino-americanos? E mais especialmente para esses jovens de camadas populares, mais desprovidos do suporte das instituições que o resto de nós?

Nesse caso, levar em conta a posição social que o indivíduo ocupa é essencial para compreender sua maneira de ver, atuar e perceber o mundo. Portanto, nosso interesse em conhecer quem são esses indivíduos não se resume a uma redução da análise sociológica ao ator, mas trata-se de analisar o processo de construção do indivíduo, inserido em determinado contexto histórico, social, político, econômico e cultural, que nos permite uma nova maneira de compreender a sociedade.

Martuccelli (2010) acentua que o indivíduo tem a capacidade de atuar de forma diversa em um contexto institucionalmente colocado, marcadamente para controlar essas variantes de ações dos sujeitos. Para o sociólogo, descrever a sociedade é explicar como se fabricam os indivíduos, portanto, entender como esses indivíduos são forjados, é explicar a formação da própria sociedade, mas de uma perspectiva diferente.

Questionamentos sobre as relações desses jovens com o espaço da escola, especialmente da EJA, sua permanência, abandono e retorno a esse espaço 
continuam sem respostas. As relações que se estabelecem entre as práticas sociais e vida escolar desses jovens também estão por serem estudadas. As discussões feitas nesse campo demonstram que a escola permanece muito distante dos sonhos, ou mesmo da realidade da juventude, embora ocupe um lugar de importância simbólica para a formação e o futuro desses jovens.

Portanto, é fundamental conhecer os caminhos percorridos pelos sujeitos, os obstáculos com os quais se depararam ao longo de sua história e os suportes aos quais recorreram para chegar no ponto em que se encontram, principalmente levando-se em conta os contextos aos quais se circunscrevem essas experiências.

Conhecer e entender os suportes criados/usados pelos jovens na EJA em Angra dos Reis pode contribuir para compreender suas trajetórias de escolarização.

\section{Os jovens e suas histórias}

Ao darmos voz a esses jovens, percebemos que a escolarização tem importância e peso para as suas vidas e sua formação. A escola é o caminho para realização do sonho de uma vida melhor, de aquisição de bens materiais, de um bom emprego. A escola é o suporte para enfrentamento das provas da vida adulta.

Embora muitas vezes suas atitudes não correspondam a essa consciência da importância da escola e da escolarização, os jovens entendem que essa é a resposta para a vida nessa sociedade, nesse contexto, como fica claro em suas respostas sobre o significado da EJA em suas vidas.

Paulo $^{7}$, por exemplo, de quinze anos, acredita ter começado a estudar aos nove anos e aos quatorze teve que parar para ajudar a complementar a renda familiar. Retornou aos quinze, já na EJA. Nesse intervalo, segundo ele, repetiu diversas vezes porque não se dedicava aos estudos.

Com o tempo passando, Paulo foi percebendo que estava ficando "para trás" e os colegas seguindo: "comecei a ver meus colegas passar de mim, me ultrapassarem e eu não aguentei, entendeu".

Com a EJA, Paulo pretende alcançar um futuro melhor, pois considera que sem estudo isso não é possível. Para o futuro, as perspectivas de Paulo são de se tornar um lutador de boxe. Outra perspectiva do jovem é entrar para o exército.

\footnotetext{
${ }^{7}$ Todos os nomes são fictícios, escolhidos pela pesquisadora ou pelos próprios entrevistados.
} 
Erick, de quinze anos, repetiu diversas vezes nos anos iniciais do Ensino Fundamental, pois não ia para a escola.

Sentindo-se deslocado entre as crianças que frequentam o diurno, pediu para passar a estudar na EJA. Neste ambiente, sente-se melhor ao lado de pessoas mais velhas e mais experientes. Além disso, considera o ensino na EJA melhor, mais rápido. Para Erick, estar na EJA é importante, pois o aproxima de seu projeto futuro que é fazer prova para ser fuzileiro.

Eduardo, de dezesseis anos, participou de cursos no Corpo de Bombeiros, experiência que lhe deixou boas lembranças e o fez desejar seguir essa carreira, com a qual, no entanto, o pai não está de acordo, pois prefere que o filho siga uma carreira federal. A única coisa certa para Eduardo é que ele pretende cursar uma faculdade, mas o curso e a carreira ainda não foram decididos.

Ana, com dezessete anos, mora com a mãe, tem um filho e trabalha na creche, onde seu filho também recebe atendimento. Começou sua vida escolar em uma instituição particular, mas teve várias interrupções. Na última vez, ficou um ano afastada, até o filho crescer e poder ser deixado com alguém, enquanto ela está na escola.

Sua mãe é seu maior exemplo e seu filho sua maior motivação. Por um lado, a jovem vê as dificuldades pelas quais a mãe, analfabeta, passou para criála junto com a sua irmã. As dificuldades que ela própria viveu para se alfabetizar sem poder contar com a ajuda da mãe e deseja poder dar para o filho uma história diferente.

Para Ana, estudar na EJA também significa acelerar seus estudos que já estão muito atrasados, além da possibilidade de conseguir um emprego, ao garantir a escolarização.

Tamara tem dezessete anos e mora com a mãe. Declara que não gostava da escola porque sentia falta de uma participação e valorização maior da sua escolarização por parte de sua mãe que, segundo ela, nunca se importou com sua vida escolar; nunca a levou a escola, nem participou de reuniões. A partir da $5^{\text {a }}$ série $\left(6^{\circ}\right.$ ano), passou a ficar retida e não conseguiu mais avançar, pois sempre abandonava a escola no meio do ano por sofrer bullying.

$\mathrm{Na}$ EJA, a jovem acredita estar "correndo atrás" do tempo perdido, e isso a possibilitará conseguir um emprego, fazer um curso no SENAC para trabalhar na Verolme ${ }^{8}$.

\footnotetext{
${ }^{8}$ Verolme - Marina e Estaleiro localizada no bairro de Jacuecanga. A Marina Verolme se intitula o maior polo náutico do Brasil, com capacidade para movimentação de embarcações de grande porte. Em sua área industrial e comercial abriga instalações de grandes estaleiros nacionais e estrangeiros. Consultar: http://www.brmarinas.com.br.
} 
Embora seu sonho para o futuro seja fazer nutrição, Tamara vê esse curso no SENAC como o primeiro passo para uma mudança e melhoria de vida. Esse primeiro passo tem sido obstaculizado pelo fato de a jovem não ter concluído o Ensino Fundamental.

Bina tem dezesseis anos, trabalha como servente de pedreiro e mora com a sua mãe. Para ele, estudar na EJA, além de adiantar seus estudos, possibilita um emprego melhor para poder juntar dinheiro e comprar uma casa para a sua mãe. Também o aproxima de seu sonho que é servir a Marinha.

Eloá, dezessete anos, tem uma filha, mora com a mãe e a irmã, não trabalha. A trajetória escolar de Eloá, como a dos demais, também foi truncada, com retenções por faltas e a saída temporária da escola quando teve a filha. Foi nesse período também que a jovem se transferiu para a EJA, para poder cuidar da filha.

Para Eloá, a EJA significa a possibilidade de conquistar um futuro melhor para a filha, para ela mesma e para os pais. Significa conseguir alcançar seu objetivo de ingressar na Polícia Civil.

Eloá relata que, se não fosse pela filha, nem estaria estudando. Mas a chegada do bebê mudou toda sua visão de mundo e agora sabe da importância dos estudos para alcançar mudanças em sua vida, atingir seus objetivos e dar um futuro melhor para a filha e para si mesma.

Adriana tem dezesseis anos, vive com mãe e não trabalha. Relata ter deixado de gostar da escola na quarta série ( $5^{\circ}$ ano), quando começou a sofrer bullying por parte de um colega, por ser negra.

Sua trajetória está cheia de abandonos motivados por mudanças de residência e para cuidar do irmão pequeno. Em 2014, retornou à escola e entrou na EJA buscando acelerar seus estudos, pois se considera muito atrasada em sua escolarização.

Para o futuro, Adriana pretende fazer o curso de administração. Pretende também ser advogada. Para Adriana, toda pessoa deveria ter mais de uma opção para garantir o emprego.

Antônio, quinze anos, mora com os pais e não trabalha. $\mathrm{O}$ início da sua escolarização foi bem difícil, pois o jovem sofreu agressões físicas constantes na escola de alunos maiores. Trocar de escola resolveu o problema das surras, mas outros problemas vieram e provocaram diversas retenções na sua vida escolar.

Hoje na EJA, o jovem vê a oportunidade para recuperar o que perdeu com esses percalços: os amigos, a família e o tempo. Busca adiantar seus estu- 
dos para alcançar os amigos que seguiram e conseguir um bom emprego e poder ajudar todos que já o ajudaram.

Catarina tem dezesseis anos e vive com o namorado/companheiro e não trabalha. Parou de estudar para cuidar da mãe doente e, quando esta morreu, retornou em 2014 para a EJA, após intervenção do Conselho Tutelar.

A jovem pretende terminar o Ensino Fundamental, mas ainda não sabe o que deseja para o futuro. Esteve um período desanimada por conta dos problemas que vivenciou em família, após o falecimento da mãe.

Jessica, quinze anos, mora com os pais e cuida do sobrinho para a irmã. A jovem passou por várias escolas. Parou de estudar por que mudou de residência e, finalmente, em 2014, transferiu-se para a EJA para ficar em casa durante o dia cuidando do sobrinho. Para o futuro, pretende fazer formação de professores e faculdade de Educação Física.

Rafael tem dezessete anos, mora com a mãe, trabalha como grafiteiro e veio de Brasília aos sete anos. Passou por várias escolas até finalmente vir para a EJA, mas não tem retenções na sua trajetória escolar.

A opção pela EJA se deu pela necessidade de trabalhar para ajudar em casa. Rafael pretende dar uma vida melhor para sua mãe e sabe que, para isso, precisa de uma formação. Por isso, considera que a EJA é o melhor caminho, pois poderá acelerar seus estudos.

Seu sonho para o futuro é abrir seu próprio atelier de grafite e realizar os sonhos da mãe de se formar: "ter um papelzinho na mão dizendo que eu me formei". Pretende fazer o curso de Designer Gráfico ou engenharia.

Como fica claro em todas as falas que esses jovens têm sonhos e expectativas de um futuro diferente, mais promissor do que seu presente e todos veem na EJA o caminho para alcançar esse objetivo. Mesmo quando não sabem exatamente o que querem para o futuro, sabem que precisam da escolarização e consideram que a Educação de Jovens e Adultos é o caminho para se chegar aos seus objetivos e, principalmente, que a modalidade é a melhor forma para recuperar o tempo perdido nos truncamentos de sua trajetória escolar.

\section{Considerações finais}

Em geral, foi possível perceber na fala dos entrevistados que eles procuram a modalidade EJA por se sentirem incomodados em sala no ensino regular por estarem se relacionando com crianças, mas também porque pretendem recuperar o tempo que consideram perdido em sua escolarização. A busca pela 
EJA para eles é também a busca pela transformação de uma realidade social dada.

Estes jovens são parte de um grupo da sociedade alijado do acesso a uma bagagem cultural que é limitada a poucos e possuem capital cultural restrito, de acordo com o que espera a nossa concepção de educação e a maioria dos educadores. Por outro lado, esses mesmos jovens vivenciam uma multiplicidade de experiências, que, no entanto, não fazem parte do rol dos conhecimentos considerados como valorativos pela escola.

Se para a escola a presença dos jovens significa uma mudança do perfil e, portanto, a necessidade de se reestruturar, de repensar sua organização e sua prática, para os jovens, a escola continua tendo importância simbólica de ascensão social e mudança em suas condições de vida.

O processo de formação desses indivíduos está carregado de provas às quais eles precisam fazer frente para alcançar sua individuação.

Diante desse quadro, os indivíduos precisam lançar mão de experiências, atitudes e maneiras de se portar que lhes possibilite enfrentar essas provas. A escola torna-se, assim, a maior prova pela qual os jovens precisam passar para realizar seus projetos pessoais e adquirir uma vida melhor do que aquela que têm hoje com seus pais, e garantir conforto para si e para a sua família.

Por outro lado, para esses jovens, os suportes estão na própria escola, que, contraditoriamente, dialeticamente também os afasta. Os colegas que se ajudam e se animam mutuamente, os próprios professores que se mostram mais pacientes e abertos a atender e entender as dificuldades dos alunos se constituem nesses suportes tão necessários e importantes para estes que não veem diante de si muitas perspectivas de uma vida diferente.

Todos têm em mente essa concepção, mesmo que a ideia não esteja muito clara e a noção faça parte muito mais do senso comum do que de uma construção consciente do sujeito. Trata-se de uma força que os impele a tentar novamente, e outra vez e diversas vezes, entrando e saindo da escola, mas sempre alimentando sonhos de mudanças, de uma vida diversa daquela que os seus pais levaram e levam. O sonho de superar as dificuldades vividas no presente e contar com um futuro menos cinza e mais colorido.

Sabemos que a escola tem representação simbólica fundamental em qualquer sociedade. O senso comum orienta para a busca da escolarização. Essa questão está presente na fala dos jovens quando afirmam que a escola representa a garantia de um futuro melhor, um bom emprego. Recuperar o tempo perdido e concluir os estudos o mais rápido possível torna-se o principal objetivo 
de quase todos eles, mesmo quando não sabem exatamente para que. O tempo possui uma dimensão importante, torna-se referência para a construção do projeto de vida de cada um.

A principal questão, no fundo, é a dificuldade e despreparo das redes e professores em lidar com as demandas apresentadas por esses jovens. Em primeiro lugar, eles embaçam o quadro que se espera encontrar na EJA. Alunos passivos, totalmente interessados naquilo que o professor tem para apresentar, mesmo que não entendam nada e não vejam nenhuma aplicabilidade prática para o que é visto na escola.

O jovem, por sua vez, traz um novo mundo de fora para dentro da escola. O mundo das suas interações, que podem ser ou não o mundo do trabalho.

Vimos na pesquisa, por exemplo, que poucos jovens trabalham e quando o fazem, não é essa a realidade que querem compartilhar nesse espaço de socialização que é a escola.

Eles estão mais interessados em dividir suas experiências, socializar, se distrair, a ficar reforçando sua realidade de trabalhador, quase sempre subempregado, com baixa remuneração e muita exploração. Esse pode ser um ponto de conflito dentro do espaço da EJA que recebe um número cada vez maior de jovens.

Esse parece ser o principal desafio para a Educação de Jovens e Adultos: o aprendizado sobre a diversidade. Lidar com a diversidade sem perder o foco da educação formal, mas compreendendo que ela não é o único, e em algumas situações, nem o melhor caminho para a formação do indivíduo.

Barrar a entrada e permanência dos jovens de 15 a 17 anos na EJA é impedi-los de realizar exatamente o sonho que todos os entrevistados declararam de recuperar o tempo perdido. E a justificativa de que eles não podem estar na EJA porque não trabalham enfraquece contra o argumento de que a educação de jovens e adultos não tem necessariamente que ser oferecida a noite.

Precisamos romper com essa estrutura pautada na alegação de que se destina ao aluno que não tem como ir para a escola durante o dia. Há muitos trabalhadores noturnos, ou mães que não tem com quem deixar seus filhos à noite. A principal dificuldade para a implementação de cursos de EJA durante o dia parece estar muito mais ligada a estrutura física das redes, que não têm salas de aula disponíveis e equipes suficientes para montar turmas do que propriamente de demanda. 
Isto posto, a pesquisa nos deixa com algumas questões que precisam ser enfrentadas por pesquisadores, professores, gestores e pelos próprios sujeitos da EJA. Que Educação de Jovens e Adultos temos e queremos construir para a diversidade de sujeitos que a procuram como caminho para realizar seus sonhos e atender suas necessidades de formação? Como gestores e professores veem a presença desses jovens e o novo perfil da EJA em Angra dos Reis? Como os alunos mais velhos encaram essa presença?

Essas questões carecem ainda de pesquisas que tragam luz sobre elas e são necessárias para a construção de uma EJA para os jovens, a partir dos 15 anos, para os adultos e para os idosos, entendida como um direito humano fundamental e subjetivo, mas atentando para as diferentes necessidades de cada um desses grupos.

Portanto, tem que fazer sentido para o sujeito a quem se destina, ou seja, estar conectada com a realidade da qual esse sujeito faz parte. Tornandose, assim, um instrumento de transformação da sociedade e superação das desigualdades sociais.

\section{Referência}

ARROYO, M. Balanço da EJA..REVEJ@ - Revista de Educação de Jovens e Adultos, Belo Horizonte. v. 1, n. 0, p. 1-108, ago. 2007.

BRASIL. Instituto Brasileiro de Geografia e Estatística. IBGE Cidades: censo demográfico 2010. Rio de Janeiro: IBGE, 2010.

. Instituto Brasileiro de Geografia e Estatística. PNAD 2011. Rio de Janeiro: IBGE, 2012.

BRASIL. Lei no 9.394 de 20 de dezembro de 1996. Lei de Diretrizes e Bases da Educação Nacional (LDB). Brasília. 1996. Biblioteca Digital da Câmara dos Deputados, Centro de Documentação e Informação, Coordenação de Biblioteca. Disponível em <http://bd.camara.gov.br> Acessa em: 08 jul. 2013.

CARRANO, P. C. R. Educação de Jovens e Adultos e Juventude: o desafio de compreender os sentidos da presença dos jovens na escola da "segunda chance”. REVEJ@ - Revista de Educação de Jovens e Adultos, Belo Horizonte. v. 1, n. 0, p. 1-108, ago. 2007. 
COSTA. M. B. da. Começar de novo: um estudo sobre percursos biográficos de jovens na EJA. 2011. Dissertação (Mestrado em Educação) - Faculdade de Educação, Universidade Federal Fluminense, Niterói, p. 129. 2011.

DAYRELL, Juarez. Muito mais que aluno - A escola como espaço sócio-cultural. In: DAYRELL, Juarez (Org.) Múltiplos olhares sobre educação e cultura. Belo Horizonte: Editora UFMG, 1996.

MARINHO, Leila M. H. de M. Entre nós e encruzilhadas: as trajetórias dos jovens de 15 a 17 anos na EJA em Angra dos Reis. Dissertação (Mestrado em Educação) - Faculdade de Educação, Universidade Federal Fluminense, Niterói, p. 160. 2015.

MARTUCCELLI, Danillo. Existem indivíduos en el Sur?1. ed. Santiago: LOM Editiones, 2010.

RIO DE JANEIRO. Secretaria Estadual de Educação. Total de Matrículas no estado do Rio de Janeiro 2014. Rio de Janeiro: SEEDUC, 2014.

VARGAS, Sônia Maria de. A atuação do departamento de Ensino Supletivo do MEC no período de 1973-79. Dissertação (Mestrado em Educação) Pontifícia Universidade Católica. Rio de Janeiro, p. 129. 1984. 
